\title{
Risk Factors for Anastomotic Leakage after Laparoscopic Rectal Resection
}

\author{
Dong Hyun Choi, Jae Kwan Hwang ${ }^{1}$, Yong Tak Ko ${ }^{1}$, Han Jeong Jang ${ }^{1}$, Hyeon Keun Shin, Young Chan Lee, \\ Cheong Ho Lim, Seung Kyu Jeong, Hyung Kyu Yang \\ Department of Colorectal Surgery, Seoul Yang Hospital, Seoul, \\ ${ }^{1}$ Department of Colorectal Surgery, Namyangju Yang Hospital, Namyangju, Korea
}

Purpose: The anastomotic leakage rate after rectal resection has been reported to be approximately $2.5-21$ percent, but most results were associated with open surgery. The aim of this study was to identify risk factors and their relationship to the experience of the surgeon for anastomotic leakage after laparoscopic rectal resection.

Methods: Between March 2003 and December 2008, 156 patients underwent a laparoscopic rectal resection without a diverting ileostomy. The patients' characteristics, the details of treatment, the intraoperative results, and the postoperative results were recorded prospectively. Univariate and multivariate analyses were applied to identify risk factors for anastomotic leakage. Results: The majority of operations were performed for malignant disease $(\mathrm{n}=150 ; 96.2 \%)$, and 96 patients $(61.5 \%)$ were males. Conversion to open surgery occurred in 1 case $(0.6 \%)$. The anastomotic leak rate was $10.3 \%(16 / 156)$, and there were no mortalities. In the univariate analysis, tumor location, anastomotic level, intraoperative events, and operation time were associated with increased anastomotic leakage rate. In the multivariate analysis, anastomotic level (odds ratio [OR], 6.855; $95 \%$ confidence interval [CI], 1.271 to 36.964 ) and operation time (OR, 8.115; 95\% CI, 1.982 to 33.222 ) were significantly associated with anastomotic leakage.

Conclusion: The important risk factors for anastomotic leakage after laparoscopic rectal resection without a diverting ileostomy were low anastomosis and long operation time. An additional procedure, such as diverting stoma, may reduce the anastomotic leakage if it is selectively applied in cases with these risk factors.

Keywords: Anastomotic leakage; Laparoscopic surgery; Rectal resection; Risk factors

\section{INTRODUCTION}

Total mesorectal excision (TME) introduced by Herald in 1982 has been accepted as the standard method for rectal surgery because it reduces the local recurrence rate, increases the sur-

Received: February 16, 2010 Accepted: July 26, 2010

Correspondence to: Seung Kyu Jeong, M.D.

Department of Colorectal Surgery, Yang Hospital, 424 Gil-dong,

Gangdong-gu, Seoul 134-814, Korea

Tel: +82-2-480-8008, Fax: +82-2-480-8119

E-mail: jsurgeon2002@yahoo.co.kr

This article was presented at the 42th meeting of the Korean Society of Coloproctology, Daegu, Korea, April 10 to 12, 2009

(C) 2010 The Korean Society of Coloproctology

This is an open-access article distributed under the terms of the Creative Commons Attribution NonCommercial License (http://creativecommons.org/licenses/by-nc/3.0) which permits unrestricted noncommercial use, distribution, and reproduction in any medium, provided the original work is properly cited. vival rate, and shows better functional results. Also, minimal invasive surgery through laparoscopic surgery was introduced in the 1990s, and it has been showing promising results not only in colon cancer but also in rectal cancer. However, neither laparoscopic surgery nor open surgery is completely secure from the risk of anastomosis leakage.

In spite of the improvement of the surgical technique and accumulated experiences, anastomotic leakage is still one of the most severe complications, with a $2.5-21 \%$ incidence rate $[1,2]$. In the Swedish Rectal Cancer Registry (SRCR) the anastomotic leakage rate was just below $10 \%$. No tendency towards improvement was found throughout a ten-year period from 1995 to 2004 [3]. The increase in sphincter-saving procedures and the subsequently higher proportion of patients with distal bowel anastomoses may contribute to an increased incidence of anastomotic failure $[4,5]$. Anastomotic leakage after rectal surgery can result in significant morbidity and mortality, and 
may be associated with a higher local recurrence rate in rectal cancer $[6,7]$. In patients, complaints caused by stoma, anxiety caused by their current state, and stress caused by additional surgery increase the incidence of complications and may adversely affect the relationship between the patient and the surgeon.

Laparoscopic rectal surgery provides an excellent operative field in a narrow pelvis, but requires more linear stapler than open surgery. Also, the experience of the surgeon is a crucial factor because it takes a long time to overcome the learning curve. According to the recent Cochrane review, there was no difference in anastomotic leakage rate between laparoscopic surgery and open surgery [8]. However, there is not many study related to anastomotic leakage after laparoscopic rectal resection, and the protective ileostomy rate, the preoperative chemoradiotherapy rate, and the TME rate in each study are not consistent, producing different results. Laparoscopic colon surgery is nationwide popular in Korea. Especially, laparoscopic rectal surgery has been expending, but study related to anastomotic leakage is rare. So, the aim of this study was to identify the risk factors of anastomotic leakage after laparoscopic rectal resection at a single center and to assess the relationship between the experience of the surgeon and the incidence of anastomotic leakage.

\section{METHODS}

\section{Patients}

From March 2003 to December 2008, 188 patients at Seoul Yang Hospital underwent laparoscopic rectal resection, and all of them were prospectively recorded in the database. Ten patients who received an abdominoperineal resection and 22 patients who were treated with neoadjuvant chemoradiotherapy and protective ileostomy (17 cases), or a protective ileostomy without neoadjuvant chemotherapy (5 cases) were excluded. Thus, 156 patients were included in this study. The characteristics of the patients and tumors, as well as the intraoperative and postoperative results, were analyzed to evaluate the relationships between all the variables and anastomosis leakage. All patients undergoing surgery gave written informed consent concerning the surgical procedure and the risks of the procedure.

\section{Surgical method}

All surgeries were accomplished by a single colorectal surgeon. The patients were placed in the modified lithotomy position, and the pneumoperitoneum was set to $12 \mathrm{mmHg}$ and was maintained at that level throughout the surgery. In most cases, an $11 \mathrm{~mm}$ subumbilical port was placed to introduce the laparoscope, and other ports were placed in the right lower quadrant (12 $\mathrm{mm}$ port), right upper quadrant ( $5 \mathrm{~mm}$ port), left lower quadrant ( $5 \mathrm{~mm}$ port), and the left upper quadrant ( $5 \mathrm{~mm}$ port).
The surgeon was located on the right side of the patient, and a medial-to-lateral dissection was done. High ligation of the inferior mesenteric artery was considered as a general principle. Low ligation was performed depending on the condition of the patient's blood vessel. Splenic flexure mobilization was done totally or partially, depending on the bowel length. In mid and low rectal cancer, TME was performed. In upper rectal cancer, a partial mesorectal excision was performed. The rectum was transsected by using a linear endoscopic stapler after checking to ensure that the safety distal resection margins were at least $5 \mathrm{~cm}$ in upper rectal cancer and $1 \mathrm{~cm}$ in low rectal cancer. For rectal extraction, a $4 \mathrm{~cm}$ to $5 \mathrm{~cm}$ long skin incision was made on the suprapubic or umbilical area, and then a wound protector was placed. After the proximal resection margin was check ed, the colon was transsected, and the anvil was then inserted. After the bowel was replaced in the abdominal cavity, the pneumoperitoneum was reestablished, and an end-to-end anastomosis was performed using a circular stapler. After anastomosis, the doughnut was checked, and an air leakage test was executed through the anus. A protective ileostomy was created in patients who received neoadjuvant chemoradiotherapy or in other patients for whom the surgeon thought it was necessary and was done by on right lower trocar site extended. A drain was inserted around the anastomosis along the presacral space. The operation time was measured from skin incision to skin closure.

\section{Definition}

The rectum was defined as $15 \mathrm{~cm}$ from the anal verge. Less than $5 \mathrm{~cm}$ from the anal verge was considered as the low rectum, $5-10 \mathrm{~cm}$ from the anal verge was considered as the mid rectum, and $10-15 \mathrm{~cm}$ from the anal verge was considered as the upper rectum.

Anastomotic leakage was defined as clinical symptoms follow as: 1) pus or fecal discharge from the drain, 2) increased temperature $\left(>38^{\circ} \mathrm{C}\right)$ or leukocyte count, or peritoneal irritation sign on physical examination, or 3) rectovaginal fistula or abscess in the pelvic cavity. Anastomotic leakage was diagnosed by digital rectal examination, sigmoidoscopy, abdominal CT, and water-soluble contrast enema. Unexpected events related to anastomosis during surgery, such as a instrument failure, ischemia of the proximal colon, tumor perforation, and additional surgery caused by anastomotic hemorrhage, were defined as 'adverse intraoperative events.'

\section{Cumulative sum (CUSUM) analysis}

A CUSUM analysis is one of the methods to analyze the learning curve and is used in colonoscopy, laparoscopic surgery, and ultrasonography [9-11]. In this research, a CUSUM analysis was used to find the relationship between surgical experience and anastomotic leakage. The CUSUM (Sn) is defined as $\mathrm{Sn}=\sum(\mathrm{Xi}-\mathrm{Xo}) ; 0$ is substituted for $\mathrm{Xi}$ when there is no anas- 
tomotic leakage and is considered a 'success', and 1 is substituted for Xi when there is anastomotic leakage and is considered a 'failure.' Xo represents the anastomotic leakage allowance rate, or failure rate. Thus, when the success rate (rate for no anastomotic leakage) is $90 \%$, the failure rate is $10 \%$, and 0.1 is substituted for Xo. When these modifications are mapped, a picture with a slope is drawn. A positive slope represents a failure rate outside the allowance range, and a negative slope represents a failure rate within the allowance range.

\section{Statistical method}

Data analysis and statistics were done by using SPSS ver. 13.0 (SPSS Inc., Chicago, IL, USA). The chi-square test and Fisher's exact test were used for categorical variable comparison and analysis. The Student's t-test was used for continuous variables. Independent risk factors for anastomotic leakage were evaluated using multivariate stepwise logistic regression analysis. The results were considered as significant when the level of significance was $95 \%$ and the P-value was less than 0.05 .

\section{RESULTS}

Patient characteristics are shown in Table 1. Among 156 patients, 96 were male and 60 were female. The average age was 61.7 years old (range, 18 to 86 years old). One hundred fifty cases $(96.2 \%)$ involved malignancies and 3 cases involved benign tumors. In 54 cases $(34.6 \%)$, the lesions were located in

Table 1. Characteristics of the 156 patients who underwent laparoscopic rectal resection without a diverting ileostomy

\begin{tabular}{lc}
\hline Variables & No. $(\%)$ \\
\hline Age (yr, range) & $61.7 \pm 12.5(18-8,690)$ \\
Male & $96(61.5)$ \\
Malignancy & $150(96.2)$ \\
Tumor location & \\
$>10$ & $54(34.6)$ \\
$5-10$ & $87(55.8)$ \\
$\leq 5$ & $15(9.6)$ \\
Operation procedure & \\
AR & $16(10.3)$ \\
LAR & $122(78.2)$ \\
ULAR & $7(4.4)$ \\
LATA resection & $11(7.1)$ \\
Anastomotic level & \\
$>$ AV 5 cm & $88(56.4)$ \\
$\leq$ AV 5 cm & $68(43.6)$ \\
Open conversion & $1(0.6)$ \\
Anastomotic leakage ${ }^{\mathrm{a}}$ & $16(10.3)$ \\
\hline
\end{tabular}

CCRT, concurrent chemoradiation therapy; AR, anterior resection; LAR, low anterior resection; ULAR, ultralow anterior resection; LATA, laparoscopic transabdominal transanal proctosigmoidectomy with coloanal anastomosis; AV, anal verge. a3 cases of rectovaginal fistula were included. the upper rectum, in 87 cases $(55.8 \%)$, they were located in the mid-rectum and in 15 cases (9.6\%), they were located in the low rectum. The surgical procedure were carried out laparoscopic anterior resection in 16 cases (10.3\%), laparoscopic low anterior resection in 122 cases (78.2\%), laparoscopic trnasabdominal and transanal proctosigmoidectomy with coloanal anastomosis (LATA resection) in 11 cases (7.1\%) and laparoscopic transabdominal ultralow anterior resection in 7 cases (4.4\%). Among these cases, only 1 case $(0.6 \%)$ was converted to open surgery. In 88 cases (56.4\%), the anastomosis site was more than $5 \mathrm{~cm}$ from the anal verge, and in 68 cases (43.6\%), it was less than $5 \mathrm{~cm}$ from the anal verge. Unexpected intraoperative events took place in 20 cases. Among them, 12 cases were related to instrument failure, such as the bending of linear staplers, failure to suture, and the disruption of distal rectal stump by circular stapler. Among them, 4 cases were related to ischemia of proximal colon, 3 cases to anastomotic hemorrhage, and 1 case to bowel perforation.

\section{Anastomotic leakage}

Among 156 patients, anastomotic leakage occurred in 16 (10.3 $\%)$ who did not receive an ileostomy, and 2 patients among those 16 had a rectovaginal fistula. Among the 22 patients who received protective ileostomy, only 1 case $(4.5 \%)$ had an anastomotic leakage. The anastomosis leakage rates were $9.0 \%$ (11 of 122 cases) for a low anterior resection, $43 \%$ ( 3 of 7 cases) for an ultralow anterior resection, and $18.2 \%$ ( 2 of 11 cases) for a LATA resection. Among the 16 patients who underwent a laparoscopic anterior resection, there was no anastomosis leakage. The mean postoperative period to be confirmed anastomotic leakage was 3 days (range, 1 to 9 days), and the two rectovaginal fistulae occurred on the postoperative 13th and 14th day, respectively. Among the 16 anastomotic leakage cases, 13 were treated with a diverting ileostomy, and 3 for whom leakage occurred within the first postoperative day were treated only with transanal irrigation and primary repair. Two of the 3 cases underwent transanal irrigation and primary repair finally had an additional ileostomy due to continuous anastomotic leakage, but 1 case was healed without any complications. The mean hospital stay was 22.8 days (range, 10 to 45 days), and the mean time to discharge after additional surgery was 18.2 days (range, 7 to 36 days). There was no death related to anastomosis leakage (Table 2 ).

\section{Relationship between anastomotic leakage and proficiency}

Fig. 1 shows the CUSUM analysis of the relationship between surgical experience and anastomotic leakage in rectal resections. The CUSUM goal success rates were set as $85 \%, 88 \%$, $90 \%, 92 \%$, and $95 \%$. When the success rate was $85 \%$ (anastomotic leakage rate 15\%), the peak was around 10th case, followed by a constant decrease and leveling out around 109th case. This shows that when the expected anastomotic leakage 
Table 2. Clinicopathologic features of anastomotic leakage patients after laparoscopic rectal resection without a diverting ileostomy $(\mathrm{n}=16)$

\begin{tabular}{lc}
\hline Variables & No. (\%) \\
\hline Mean age (yr, range) & $56.6(37-76)$ \\
Male & $11(68.8)$ \\
Mean BMI (kg/m², range) & $22.6(18.8-26.1)$ \\
Operation procedure & \\
LAR & $11(68.8)$ \\
ULAR & $3(18.8)$ \\
LATA resection & $2(12.5)$ \\
Anastomotic level & \\
$>$ AV 5 cm & $2(12.5)$ \\
$\leq$ AV 5 cm & $14(87.5)$ \\
Detection time ${ }^{a}$ (day) & \\
Pelvic leakage (range) & POD $3.0(1-9)$ \\
Rectovaginal fistula (range) & $13.5(13-14)$ \\
Treatment & \\
Ileostomy & 13 \\
Transanal repair $\rightarrow$ ileostomy & 2 \\
Transanal repair & 1 \\
Length of hospital stay (days, range) & $22.8(10-45)$ \\
Mortality & 0 \\
\hline B
\end{tabular}

BMI, body mass index; LAR, low anterior resection; ULAR, ultralow anterior resection; LATA, laparoscopic transabdominal transanal proctosigmoidectomy with coIoanal anastomosis; AV, anal verge; POD, postoperation day.

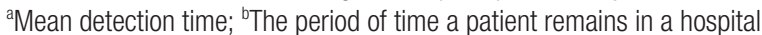

rate is set as $15 \%$, it can be reduced constantly after 10 cases, after which the surgeon can show an acceptable anastomotic leakage rate. When the success rate was $88 \%$ (anastomotic leakage rate $12 \%$ ), the peak was around 18th case, followed by a decrease until 109th case and an increase after that. This shows that when the anastomotic leakage rate is set to be $12 \%$, the rate is acceptable after 18 cases, but will later show an increase to greater than $12 \%$. Similar results were obtained when it was set to $90 \%$. When the success rate was set to be $92 \%$ (anastomotic leakage rate $8 \%$ ), the peak was reached around 50th case, followed by a decrease until 109th case, after which it increased. This shows that when the anastomotic leakage rate is $8 \%$, an acceptable leakage rate is achieved after 50th case, but later increases to more than $8 \%$ around 109 th case. For a $95 \%$ success rate (anastomotic leakage rate 5\%), the leakage rate showed a decrease after 50th case and later an increase after 95th case. This shows that it is difficult to reduce the anastomotic leakage rate to less than $5 \%$ both in the beginning and at the end of the series. Based on the time period during which the surgery was performed, July 2006 was set as the first half, and the anastomotic leakage rate for the first half was compared with that for the second half. In the first half, anastomotic leakage rate occurred in 7 of 76 cases (9.2\%), and in the second half, it occurred in 9 of 80 cases (11.3\%), but this difference did not show statistical significance $(\mathrm{P}=0.675)$.

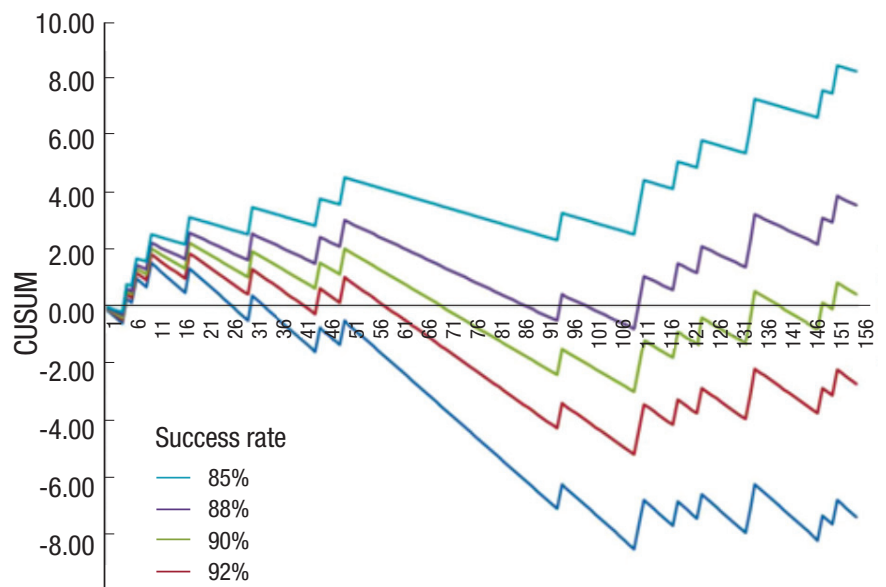

No. of cases

Fig. 1. Success rate for a laparoscopic rectal resection without a diverting ileostomy as a function of the number of cases. The curves represent a cumulative sum (CUSUM) analysis for anastomotic leakage, calculated for target success rates of $85 \%, 88 \%, 90 \%, 92 \%$, and $95 \%$ respectively. 'Failure' means an anastomotic leakage after a laparoscopic rectal resection without a diverting ileostomy. Upward slopes indicate that the rate of failure exceeds the acceptable failure rate whereas downward slopes indicate that the rate of failure falls within the acceptable rate range.

\section{Risk factors related to anastomotic leakage}

According to the univariate analysis, the factors showing a significant relationship to anastomotic leakage rate were a lesion location less than $10 \mathrm{~cm}$ from the anal verge $(P=0.007)$, an anastomotic region less than $5 \mathrm{~cm}$ from the anal verge $(\mathrm{P}<$ $0.001)$, unexpected events during surgery $(P=0.036)$, and a long operation time $(\mathrm{P}<0.001)$ (Table 3$)$. In the multivariate analysis, the factors affecting anastomotic leakage rate were anastomotic location which is within $5 \mathrm{~cm}$ from the anal verge $(\mathrm{P}=$ $0.025 ; 95 \%$ confidence interval [CI], 1.271 to 36.964 ) and long operation time ( $\mathrm{P}=0.004 ; 95 \% \mathrm{CI}, 1.982$ to 33.222 ) (Table 4 ).

\section{DISCUSSION}

Anastomotic leakage is a disease that no colorectal surgeon can keep away regardless of his or her experience. Anastomotic leakage can cause severe complications, and mostly require emergency surgery. Also, $25-37 \%$ of patient deaths related to colorectal surgery have been known to be related with anastomotic leakage [12]. Regarding risk factors of anastomotic leakage, the diverting ileostomy rate, the preoperative chemoradiotherapy rate, and the TME rate are not consistent among different researchers and so it is difficult to compare them in a single batch. However, if we can predict the risk factors that affect anastomotic leakage and do proper management like protective ileostomy, anastomotic leakage rate and serious complications related would be reduced $[13,14]$. This study was based 
Table 3. Univariate analysis of the risk factors for anastomotic leakage in the 156 patients undergoing a laparoscopic rectal resection without a diverting ileostomy

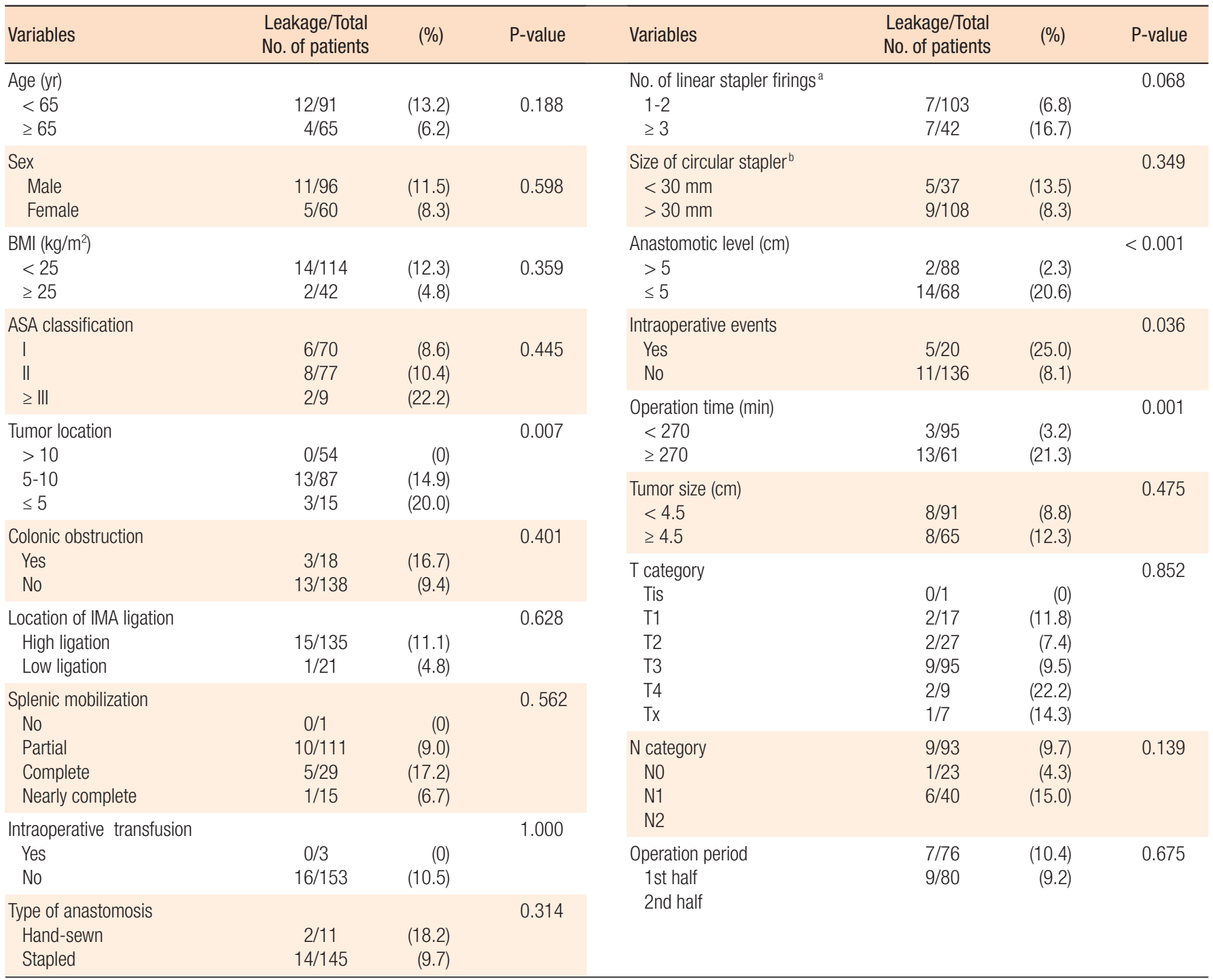

BMI, body mass index; ASA, American Society of Anesthesiologists; IMA, inferior mesenteric artery.

${ }^{a}$ Number of stapler firings during the rectal division. Coloanal anastomosis cases were not included; ${ }^{\text {b}}$ Size of circular stapler used during colorectal anastomosis. Coloanal anastomosis cases were not included.

Table 4. Multivariate analysis of the risk factors for anastomotic leakage in the 156 patients undergoing a laparoscopic rectal resection without a diverting ileostomy

\begin{tabular}{lccc}
\hline Variables & P-value & Odds ratio & $\begin{array}{c}95 \% \text { Confidence } \\
\text { interval }\end{array}$ \\
\hline Anastomotic level & 0.025 & 6.855 & $1.271-36.964$ \\
Operation time & 0.004 & 8.115 & $1.982-33.222$ \\
Intraoperative events & 0.072 & 3.730 & $0.888-15.659$ \\
\hline
\end{tabular}

on surgical results provided by a single surgeon in a single hospital. Patients with preoperative chemoradiotherapy or a pro- tective ileostomy were excluded from the analysis. Thus, this study excludes the confounding factors that are seen in research involving numerous surgeons or including an ileostomy.

The cause of anastomotic leakage has been not yet clearly understood, and anastomotic leakage has been known to have multiple causes. In rectal resection, the pelvic cavity is narrow, and it is difficult to approach the surgical area. Shortening of proximal colon can result in tension to the anastomosis area. Poor blood supply can cause ischemia of anastomotic site. And hemorrhage can result in a hematoma and septic inflammation in pelvic cavity. Eventually all of them would be related anastomotic leakage [15]. In this study, we could find out some lim- 
Table 5. Risk factors for anastomotic leakage after a rectal resection

\begin{tabular}{|c|c|c|c|c|c|c|c|}
\hline Author & Year & No. & Op type & $\begin{array}{l}\text { Protective } \\
\text { stoma (\%) }\end{array}$ & $\begin{array}{l}\text { Preoperative } \\
\text { RT rate (\%) }\end{array}$ & $\begin{array}{c}\text { Leakage rate } \\
(\%)\end{array}$ & Risk factors \\
\hline Rullier [2] & 1998 & 272 & Open & 41.9 & 11.8 & 12 & $\begin{array}{l}\text { Male } \\
\text { Level of anastomosis }(5 \mathrm{~cm}) \\
\text { Obesity }\end{array}$ \\
\hline Yeh [22] & 2005 & 978 & Open & 10 & NA & 2.8 & $\begin{array}{l}\text { Use of an irrigation suction drain } \\
\text { Blood transfusion } \\
\text { Poor colon preparation } \\
\text { Anastomotic level }(\leq 5 \mathrm{~cm})\end{array}$ \\
\hline Jestin [37] & 2007 & 372 & Open & 47.8 & 47.8 & 9.7 & $\begin{array}{l}\text { Adverse intraoperative events } \\
\text { Low anastomosis }(6 \mathrm{~cm}) \\
\text { Preoperative RT }\end{array}$ \\
\hline Lee [16] & 2007 & $\begin{array}{r}107 \\
90\end{array}$ & $\begin{array}{l}\text { Lapa } \\
\text { Open }\end{array}$ & $\begin{array}{l}24.3 \\
20\end{array}$ & $\begin{array}{l}6.5 \\
6.7\end{array}$ & $\begin{array}{r}13.6 \\
6.9\end{array}$ & No. of linear stapler firings \\
\hline Ito [18] & 2008 & 180 & Lapa & 0.6 & 0 & 5 & $\begin{array}{l}\text { TME } \\
\text { No. of stapler }(\geq 3)\end{array}$ \\
\hline Current study & 2010 & 156 & Lapa & 0 & 0 & 10.3 & $\begin{array}{l}\text { Low anastomosis }(\leq 5 \mathrm{~cm}) \\
\text { Operation time }\end{array}$ \\
\hline
\end{tabular}

Op, operation; RT, radiation therapy; NA, not accessible; Lapa, laparoscopic; ULAR, ultralow anterior resection; TME, total mesorectal excision.

itation of double stapling technique, which can create a weak point against safety of anastomosis on crossing area between linear stapler and circular stapler. In many cases, the staple was found to be bent when the doughnut was checked after anastomosis.

In laparoscopic surgery, excising the rectum perpendicularly is relatively difficult comparing with open surgery. Also, in many cases, two or more staplers are needed, and the incision line is not clean. However, the surgical view of laparoscopic surgery is excellent, enabling autonomic nervous system to be preserved better and anastomotic leakage to be diagnosed earlier. Lee et al. [16] reported that the diagnostic period of anastomotic leakage in laparoscopic surgery was faster, with an average of 2.7 days, than it was in open surgery, with an average of 5.2 days. In this study, leakage within the pelvic cavity, except rectovaginal fistula, was diagnosed on the 3rd day; showing not much difference from their report. Also, laparoscopic surgery makes the reoperation to be able to do laparoscopically like peritoneal irrigation or creation of ileostomy. In this study, 10 out of 15 cases whose ileostomy was created due to anastomotic leakage underwent laparoscopic surgery, and nowadays it has become 1st choice of treatment method in our hospital. Risk factors related to anastomotic leakage are reported as height of the anastomosis, sex, obesity, insertion of a drainage tube, ASA score, operation time, intraoperative transfusion, steroid usage, and preoperative radiotherapy (Table 5). The anastomotic leakage rate after a laparoscopic rectal resection is 5-17\%, and there is not much difference when compared with open surgery. When ileostomy is created for fecal diversion, the rate is known to be decreased [16-18]. In this study, 9.6\% (17 out of 178 cases) of the patients had anastomotic leakage when patients with a protective ileostomy creation were included, and $10.3 \%$ of the patients had leakage when patients with a protective ileostomy creation were excluded. The results were not different from those of previous study. According to Ito et al. [18] anastomotic leakage rate after laparoscopic rectal resection was $5 \%$ but the leakage rate after the laparoscopic TME was $12 \%$. They insisted that TME is the most important risk factor for anastomotic leakage. Also, cases in which three or more linear staplers were used showed a greater rate of anastomotic leakage than cases in which 2 or fewer were used $(15 \%$ vs. $3 \%$ ), and the number of linear stapler is reported as an important risk factor. In our study, $16.7 \%$ of the cases in which 3 or more linear staplers were used had anastomotic leakage whereas only $6.8 \%$ of the cases in which 2 or fewer linear staplers were used had leakage. Although there was no statistical significance to this difference $(\mathrm{P}=0.068)$, efforts to reduce the number of linear staplers to 2 or/and less seem to be warranted. To prevent anastomotic leakage, tension-free anastomosis with maintained circulation is important. Karanjia et al. [4] reported 
that the patient group without mobilization of the splenic flexure had a greater anastomotic leakage rate than the group with mobilization ( $22 \%$ vs. $9 \%$ ). They insisted that complete splenic mobilizaiton needs to be done thoroughly before stapling. Also, in cases where the anastomotic leakage risk is high, checking bowel continuity by an anastomotic leakage test is important. Ricciardi et al. [19] reported that lack of an air leakage test increases the anastomotic leakage rate significantly and such a test is also useful for testing the integrity. In our study, an air leakage test was done in every case involving double stapling in order to confirm the completeness of anastomosis. Five of 178 cases $(3.2 \%)$, including patients with leostomy creation, had air leakage. Two cases had a transanal reinforcement suture, 1 case had ileostomy creation, 1 case had reanastomosis and ileostomy creation, and 1 case had a failure in transanal suture and had ileostomy creation after conversion to open surgery. Among these five cases, there were no patients with anastomotic leakage, and one patient had anastomotic stricture. Hence, reviewing the completeness of anastomosis through an air leakage test and reinforcing sutures or re-stapling when there is leakage seem to be necessary.

Moran and Heald [20] reported that in all cases where anastomosis was done on $6 \mathrm{~cm}$ or less in TME, a defunctioning ileostomy was created or soft silicone stent was positioned through the anus to prevent anastomotic leakage. Those authors insisted that transanal decompression was not invasive and was a safe temporary treatment. However, Bulow et al. [21] concluded through a randomized study that transanal decompression did not reduce anastomotic leakage. In our study, a transanal drainage tube was not inserted, but a transabdominal drainage tube was inserted into the pelvic cavity through a $5 \mathrm{~mm}$ trocar to prevent hematoma and to detect anastomotic leakage early. It was removed 5 to 7 days after the surgery. Yeh et al. [22] from prospective study concluded that routine use of pelvic drainage after rectal resection is not justified and should be discouraged, because the insertion of an irrigation-suction drain in the pelvic cavity could act as risk factor. However, according to some studies, postoperative drainage tube insertion in the pelvic cavity reduces anastomotic leakage and complications $[5,23]$. Especially, after a TME, a huge retrorectal space is created. Blood or exudates can gather in this space and create a hematoma, seroma, bacteria proliferation, and severe infection, which will eventually induce anastomotic leakage. Thus, pelvic drainage may suppress these processes. Although there is still debate between researchers about whether drainage tube insertion affects anastomotic leakage, drain insertion must be executed selectively after considering the patient's condition and the operation methods. Observing the color of the drainage tube might be helpful in diagnosing anastomotic leakage. However, a change in the patient's condition often comes before a change in tube color in anastomotic leakage. Thus, thoroughly observing the patient after surgery is $t$ more important than depending on the drainage tube.

As above, numerous methods are being developed in order to prevent anastomotic leakage. However, J-pouch anastomosis and protective ileostomy for fecal diversion are known to be useful evidence-based treatments for preventing anastomotic leakage [15]. Hallbook et al. [24] compared the J-pouch anastomosis group and the end-to-end anastomosis group through a prospective randomized study. The J-pouch group's leakage rate was $2 \%$, which was significantly lower than that of the endto-end anastomosis group (15\%). Explanations for this difference in leakage rate between the two techniques include the full mobilization of the descending colon, which is necessary for the construction of the J-pouch, and the "filling" of the pelvis by the colon, which improves hemostasis and reduces the dead space [25]. There is still debate about whether a preventive diverting ileostomy will prevent anastomotic leakage. Matthiessen et al. [13] suggested in a randomized multicenter study that an ileostomy can reduce anastomosis leakage in a low anterior resection, but Gastinger et al. [26] insisted that an ileostomy should be done selectively because it reduces neither the anastomotic leakage rate nor the re-hospitalization rate, because additional surgery might be needed for ileostomy restoration (additional cost), and because complications might occur during a reoperation [26-28]. However, it is generally agreed that an diverting ileostomy can reduce the incidence of the severe complications that anastomotic leakage can bring.

According to some researchers, the surgeon's experience and proficiency affect not only the postoperative results and complications but also the prognosis for the patient [29-31]. In our study, the relationship between surgical experience and the anastomotic leakage rate was analyzed. Although the data were from a single surgeon in a single hospital, we found that the anastomotic leakage rate was difficult to reduce even though the surgical experience increased. This is thought to have resulted from an increase in the numbers of difficult surgeries and of lowlying anastomoses as the surgeon gained surgical experience.

In our study, an anastomotic region less than or equal to $5 \mathrm{~cm}$ from the anal verge and a long operation time were the only two factors related to anastomotic leakage. Fourteen out of 16 leakage cases (87.5\%) had anastomosis within $5 \mathrm{~cm}$ from the anal verge, and the location of anastomosis of other two cases was $5.5 \mathrm{~cm}$ and $7 \mathrm{~cm}$ from the anal verge, respectively. LopezKostner et al. [32] reported that when the anastomotic location was $15 \mathrm{~cm}$ or farther from the anal verge, the anastomotic leakage rate was $0.14 \%$, when the anastomosis location was between $10 \mathrm{~cm}$ to $15 \mathrm{~cm}$ from the anal verge, the rate is $5.4 \%$, and when the region was less than $10 \mathrm{~cm}$ from the anal verge, the rate was $8.4 \%$, showing that the rate increased as the distance from the anal verge decreased. Rullier et al. [2] also reported that the anastomotic leakage rate for anastomosis locations within $5 \mathrm{~cm}$ was 6.5 times greater than it was for locations outside $5 \mathrm{~cm}$. In our study, the anastomotic leakage rate was 10 times higher 
(20.6\% vs. $2.3 \%)$ when the anastomotic region was located with in $5 \mathrm{~cm}$. Especially, 43\% ( 3 of 7) of the cases where an ultralow anterior resection was executed showed anastomotic leakage. Thus, a preventive diverting ileostomy should be considered in cases where the anastomotic location is very low.

Although operation time is well known to be one of the risk factors for anastomotic leakage $[33,34]$, the proficiency of the surgeon is also thought to act as confounding variable in unexpected occurrences, as is the difficulty of the surgery. In patients with severe obesity, in male patients with a narrow pelvis and in cases of adverse intraoperative events, the operation will be delayed. Also, when the operation time is long, bacteria exposure and tissue damage will increase, which will cause inflammation, ultimately increasing the anastomotic leakage rate [35]. Komen et al. [36] reported that in a multivariate analysis, "after hours" construction of an anastomosis was one of independent risk factors for colorectal anastomotic leakage, in those technical difficulties and surgeon's proficiency affected the result and ileostomy creation might be considered. In our study, when the operation procedure was delayed, the possibility for anastomotic leakage was approximately 6.7 times greater than it was when the operation procedure was not delayed. Accordingly, the possibility of anastomotic leakage must be considered in cases whose the operation is delayed.

Along with the development of operation techniques and stapling devices, efforts to develop a more stable tool are being made. Thus, anastomotic leakage after colorectal surgery will be reduced in the future.

Anastomotic leakage after laparoscopic rectal resection can often occur independently even while surgical experience is ongoing, so caution is needed at all times. Especially, the anastomotic leakage rate is high when the anastomotic location is low and the operation time is long. Thus, the surgeon must decide if preventive treatment such as a diverting ileostomy needs to be done in order to reduce the risk of anastomotic leakage.

\section{CONFLICT OF INTEREST}

No potential conflict of i nterest relevant to this article was reported.

\section{REFERENCES}

1. Yoon SJ, Kim JS, Min BS, Kim NK, Baik SH, Lee KY, et al. Risk factors for anastomotic leakage after a low anterior resection for rectal cancer. J Korean Soc Coloproctol 2007;23:365-73.

2. Rullier E, Laurent C, Garrelon JL, Michel P, Saric J, Parneix M. Risk factors for anastomotic leakage after resection of rectal cancer. Br J Surg 1998;85:355-8.

3. Pahlman L, Bohe M, Cedermark B, Dahlberg M, Lindmark G, Sjodahl R, et al. The Swedish rectal cancer registry. Br J Surg 2007;
94:1285-92.

4. Karanjia ND, Corder AP, Bearn P, Heald RJ. Leakage from stapled low anastomosis after total mesorectal excision for carcinoma of the rectum. Br J Surg 1994;81:1224-6.

5. Peeters KC, Tollenaar RA, Marijnen CA, Klein Kranenbarg E, Steup WH, Wiggers T, et al. Risk factors for anastomotic failure after total mesorectal excision of rectal cancer. Br J Surg 2005;92: 211-6.

6. Bell SW, Walker KG, Rickard MJ, Sinclair G, Dent OF, Chapuis $\mathrm{PH}$, et al. Anastomotic leakage after curative anterior resection results in a higher prevalence of local recurrence. Br J Surg 2003; 90:1261-6.

7. Jung SH, Yu CS, Choi PW, Kim DD, Park IJ, Kim HC, et al. Risk factors and oncologic impact of anastomotic leakage after rectal cancer surgery. Dis Colon Rectum 2008;51:902-8.

8. Schwenk W, Haase O, Neudecker J, Muller JM. Short term benefits for laparoscopic colorectal resection. Cochrane Database Syst Rev 2005;(3):CD003145.

9. Williams SM, Parry BR, Schlup MM. Quality control: an application of the cusum. BMJ 1992;304:1359-61.

10. Choi DH, Jeong WK, Lim SW, Chung TS, Park JI, Lim SB, et al. Learning curves for laparoscopic sigmoidectomy used to manage curable sigmoid colon cancer: single-institute, three-surgeon experience. Surg Endosc 2009;23:622-8.

11. McCarter FD, Luchette FA, Molloy M, Hurst JM, Davis K Jr, Johannigman JA, et al. Institutional and individual learning curves for focused abdominal ultrasound for trauma: cumulative sum analysis. Ann Surg 2000;231:689-700.

12. Marra F, Steffen T, Kalak N, Warschkow R, Tarantino I, Lange J, et al. Anastomotic leakage as a risk factor for the long-term outcome after curative resection of colon cancer. Eur J Surg Oncol 2009;35:1060-4.

13. Matthiessen P, Hallbook O, Rutegard J, Simert G, Sjodahl R. Defunctioning stoma reduces symptomatic anastomotic leakage after low anterior resection of the rectum for cancer: a randomized multicenter trial. Ann Surg 2007;246:207-14.

14. Eberl T, Jagoditsch M, Klingler A, Tschmelitsch J. Risk factors for anastomotic leakage after resection for rectal cancer. Am J Surg 2008;196:592-8.

15. Taflampas P, Christodoulakis M, Tsiftsis DD. Anastomotic leakage after low anterior resection for rectal cancer: facts, obscurity, and fiction. Surg Today 2009;39:183-8.

16. Lee DS, Youk EG, Choi SI, Lee DH, Kim DS, Moon HY. Anastomotic leakage after laparoscopic versus open resection for rectal cancer: a retrospective study. J Korean Soc Coloproctol 2007;23: 350-7.

17. Morino M, Parini U, Giraudo G, Salval M, Brachet Contul R, et al. Laparoscopic total mesorectal excision: a consecutive series of 100 patients. Ann Surg 2003;237:335-42.

18. Ito M, Sugito M, Kobayashi A, Nishizawa Y, Tsunoda Y, Saito N. Relationship between multiple numbers of stapler firings during rectal division and anastomotic leakage after laparoscopic rectal 
resection. Int J Colorectal Dis 2008;23:703-7.

19. Ricciardi R, Roberts PL, Marcello PW, Hall JF, Read TE, Schoetz DJ. Anastomotic leak testing after colorectal resection: what are the data? Arch Surg 2009;144:407-11.

20. Moran BJ, Heald RJ. Risk factors for, and management of anastomotic leakage in rectal surgery. Colorectal Dis 2001;3:135-7.

21. Bulow S, Bulut O, Christensen IJ, Harling H. Transanal stent in anterior resection does not prevent anastomotic leakage. Colorectal Dis 2006;8:494-6.

22. Yeh CY, Changchien CR, Wang JY, Chen JS, Chen HH, Chiang JM, et al. Pelvic drainage and other risk factors for leakage after elective anterior resection in rectal cancer patients: a prospective study of 978 patients. Ann Surg 2005;241:9-13.

23. Gingold BS, Jagelman DG. Value of pelvic suction-irrigation in reducing morbidity of low anterior resection of the rectum: a tenyear experience. Surgery 1982;91:394-8.

24. Hallbook O, Pahlman L, Krog M, Wexner SD, Sjodahl R. Randomized comparison of straight and colonic J pouch anastomosis after low anterior resection. Ann Surg 1996;224:58-65.

25. Hallbook O, Sjodahl R. Anastomotic leakage and functional outcome after anterior resection of the rectum. Br J Surg 1996;83: 60-2.

26. Gastinger I, Marusch F, Steinert R, Wolff S, Koeckerling F, Lippert $\mathrm{H}$. Protective defunctioning stoma in low anterior resection for rectal carcinoma. Br J Surg 2005;92:1137-42.

27. Gooszen AW, Geelkerken RH, Hermans J, Lagaay MB, Gooszen HG. Temporary decompression after colorectal surgery: randomized comparison of loop ileostomy and loop colostomy. Br J Surg 1998;85:76-9.

28. Koperna T. Cost-effectiveness of defunctioning stomas in low an- terior resections for rectal cancer: a call for benchmarking. Arch Surg 2003;138:1334-8.

29. Cong ZJ, Fu CG, Wang HT, Liu LJ, Zhang W, Wang H. Influencing factors of symptomatic anastomotic leakage after anterior resection of the rectum for cancer. World J Surg 2009;33:1292-7.

30. Fielding LP, Stewart-Brown S, Blesovsky L, Kearney G. Anastomotic integrity after operations for large-bowel cancer: a multicentre study. Br Med J 1980;281:411-4.

31. McArdle CS, Hole D. Impact of variability among surgeons on postoperative morbidity and mortality and ultimate survival. BMJ 1991;302:1501-5.

32. Lopez-Kostner F, Lavery IC, Hool GR, Rybicki LA, Fazio VW. Total mesorectal excision is not necessary for cancers of the upper rectum. Surgery 1998;124:612-7.

33. Marusch F, Koch A, Schmidt U, Geibetaler S, Dralle H, Saeger $\mathrm{HD}$, et al. Value of a protective stoma in low anterior resections for rectal cancer. Dis Colon Rectum 2002;45:1164-71.

34. Vignali A, Fazio VW, Lavery IC, Milsom JW, Church JM, Hull TL, et al. Factors associated with the occurrence of leaks in stapled rectal anastomoses: a review of 1,014 patients. J Am Coll Surg 1997;185:105-13.

35. Makela JT, Kiviniemi H, Laitinen S. Risk factors for anastomotic leakage after left-sided colorectal resection with rectal anastomosis. Dis Colon Rectum 2003;46:653-60.

36. Komen N, Dijk JW, Lalmahomed Z, Klop K, Hop W, Kleinrensink GJ, et al. After-hours colorectal surgery: a risk factor for anastomotic leakage. Int J Colorectal Dis 2009;24:789-95.

37. Jestin P, Pahlman L, Gunnarsson U. Risk factors for anastomotic leakage after rectal cancer surgery: a case-control study. Colorectal Dis 2008;10:715-21. 